\title{
Research on Connotation, Mechanism and Realization Way of "Going-global" Inland Open Economy and the "Bringing in" Inland Resource Economy in Sichuan Province
}

\author{
Zeng Liyun ${ }^{1,2, *}$, Mao Yunyi ${ }^{3}$ \\ ${ }^{1}$ Rattanakosin International College of Creative Entrepreneurship, Rajamangala University of Technology, Rattanakosin - RICE, Bangkok, \\ Thailand \\ ${ }^{2}$ Civil and Architecture Engineering School, Panzhihua University, Panzhihua, China \\ ${ }^{3}$ Economics and Management School, Panzhihua University, Panzhihua, China
}

Email address:

nonsar@foxmail.com (Zeng Liyun)

*Corresponding author

To cite this article:

Zeng Liyun, Mao Yunyi. Research on Connotation, Mechanism and Realization Way of "Going-global” Inland Open Economy and the

"Bringing in" Inland Resource Economy in Sichuan Province. Journal of Business and Economic Development.

Vol. 5, No. 2, 2020, pp. 108-112. doi: 10.11648/j.jbed.20200502.17

Received: April 24, 2020; Accepted: June 4, 2020; Published: June 15, 2020

\begin{abstract}
Under the macro background of the continuous deterioration of the international trade environment, the policy of "One Belt and One Road" is deeply constructed, and new industrialization and urbanization are highly integrated [1]. According to the single model of eastward opening-up, the purpose is to eliminate some unfavorable effects, including the aggravated trade frictions, the recessional resource-based industries, the extensive promotion between informatization and industrialization and the uneven regional economic development [2]. Under this circumstance, Sichuan has successively launched a series of major countermeasures for the implementation of regional openness, undertaking of industry transition, and the international cooperation on production capacity. In light of the internal relationship between "going global" and "bringing in" strategy, the research analyzes the necessity, feasibility and regularity of the transition from the Inland Resource Economy (IRE) to the Inland Open Economy (IOE). It reveals that the basic connotation and formative mechanism of the "going global" IOE. The research method is comparative analysis of two regional development models, including the basic conditions, main objectives, core contents, industrial patterns and realizable way. This article demonstrates that rationality of the stages and applicability of regions, how the output of production capacity replaces output of factors, and how a resource-driven mode changes to an openness-driven mode.
\end{abstract}

Keywords: Regional Openness, Industrial Undertaking, Capacity Cooperation, Realization Way

\section{Introduction}

Sichuan is an inland province in West China, where is limited by the multiple constraints with geographical location, resources endowment and traffic conditions. The province has implemented the strategy of "openness to the eastern areas", and it is characterized by labor export as well as resource and energy supply with the advantages of low cost in production factors. With the core of Inland resource's development and on the way to factors output, the recourse-dominated economy system based on the demand-oriented East China is vigorously developed in Sichuan province [3]. These elements are concentrated in the following two aspects. (i) Based on the local labor factors and mineral resources, geographical advantages and location allocation functions are supported from the eastern regions; in the formation of factors output, the province can directly participate in the domestic industrial chain led by these eastern region; while, in the form of products output, it can be indirectly embed the global value chain led by developed countries. Thus, both a tiered open pattern of "Sichuan opens a way to the east of China, east areas open a way to overseas", and regional circulation way of "Sichuan Resources, Eastern Production, European and American markets" will come into being. (ii) Having said that, 
the investment induction and combined effects of industries are based on the utilization of resources such as steel and coal; the industrialization is carried out with mining of mineral resources and processing of products as dominated industry, and the urbanization is developed in focus on the construction of mineral sites; then it will be rapidly formed into the industry patterns and distribution patterns of "trinity", which contains resource-rich region, heavy-focused industry system and resource-based cities. "bringing in" Inland Resource Economy (IRE) can be defined as the economic pattern of regional constraint, resource-guided, external demand-driven, and factors output, and it is an inland development model of "the opening up of pilot areas, the development of miner industries, and the construction of mine-based cities". IRE is endogenous in coastal processing trade model of "Markets Replace Technologies" and derived from the multiple levels among recourses, industries and markets.

In the report of the 19th National Congress of the Communist Party of China, the opening-up orientation and policy requirements of "linkage between the land and the coastal areas, and mutual cooperation between the east and the west" are proposed. From there, inland hinterland turns into an opening-up frontier, and an inland open economy (IOE) based on "going out" capacity is vigorously developed. It can be summarized as follows. (i) It follows that the factors spread, technological discontinuity and industrial range are among different regions; it will widely undertake Chinese and foreign industries transfer through opening up to the east; and accelerate the establishment of an advanced industrial system which endogenously adapts to regional resource endowments and industrial development. (ii) While, the paper focuses on the adaptation to the phased differences in the industrialization process and the huge capacity demand for infrastructure construction; high-quality surplus production capacity is exported from the south of China to the Southeast Asian region; the serious excess structural capacity is resolved in the country; meanwhile, the regional integration and industrialization of infrastructures are accelerated in Southeast Asia. As a consequence, the cross-regional circulation way is constructed by the form of "East Industry, Made in Sichuan, ASEAN Market", and the comprehensive opening-up patterns are developed by mode of "Relying on the Great Southwest, taking advantage of Guangdong, Hong Kong and Macao, connecting with the Yangtze River Delta, and opening to Southeast Asia" [4].

\section{What It Means: The Mechanism of "Regional Openness, Industrial Undertaking, Capacity Cooperation"}

Under the dynamic environment of technological changes, industrial upgrades, and market openness, the factor cost at the eastern coastal areas in China has increased, the constraints and conflicts between resources and environment have gotten aggravated, and industrial competition has been growing fierce [5]. Now, the traditional circulation way faces the double risks which are loss of cost advantages in upstream and reduction of terminal demand in downstream. But the transportation infrastructures vis-à-vis the vast inland areas are increasingly improved, the capability of industrial development is constantly ameliorated, and the endogenous power is gradually upgraded. Thus, it highlights the inherent necessity and inevitability to implement regional openness in the inland Sichuan province. Simultaneity, a new wave of industrial transfer is constant fluctuating all around the world [6]. In China, the capital and advanced science-and-technology intensive industries are faced with the "high-end return" from the "re-industrialization" in developed countries. There has been a mode of "mid-end and low-end transfer" caused by alternative competition of resources and labor intensive industries which are low-end in developing countries. The industrial transfer tendency of "high-end return, low-end diversion" and this situation of differentiation competition can reconstruct the internal correlation and interaction among resources, industries and markets. Thus, it totally illustrates the practicability and rationality of industrial undertaking. Furthermore, China is known as the largest developing country with a grand trade surplus, and Chinese trade in products is facing severe frictions with developed economies, and then cooperation with emerging economies has released great vitality in production capacity. From a dynamic perspective, the new global trade competition and cooperation methods show that it is essential to examine and evaluate the risks, characteristics and potentials of developed markets and emerging markets. With the development process, the multiple advantages of foreign trade products, extreme carrying capacity of foreign demand markets, and the dynamic applicability of the cooperation methods have pivotal roles to play in inland foreign trade. While, it reveals the superiority and inherent regularity of international cooperation of production capacity.

Essentially, IRO is opening up to a single direction and is a single-circulation way, which contains "Sichuan Resources, Eastern Production, European and American Markets". While, the "going out" IOE is different from IRO. Through capital moving westward, industry moving inward, and output mode of capacity, IOE replaces the traditional factors output in single direction [7]. IOE builds a two-way regional openness and a two-way circulation value chain, which include developed economies in the inland hinterland and the European and American areas, and emerging economies in the Southeast Asian.

As shown in Figure 1, IOE is characterized by regional openness, industrial undertaking, and capacity cooperation, and it has a richer and deeper connotation than the inland resource characterized by factors output. First, through the synergistic promotion of opening eastward and southward, the study shows that the inland hinterland changes to the open frontier with the advantage of geographic location, and IOE attaches importance to deepening the interactive relationship among domestic factors, industries and markets; simultaneously, the transfer of industrial undertaking and outward capacity output are emphasized the dynamic 
relationship at the aggregate level and the multiple equilibrium states at the structural level. Second, in terms of trade objects, IOE changes the focal point from the products in the North-South trade to the cooperation of production capacity in the South-South trade; the trade mode is converted from the factors output and product output to the capital output and capacity output; the opening mode gives priority to the complementary and comprehensive utilization of the advantages between "bring in" of industry and "going out" of capacity. Third, transportation conditions are improved; IOE

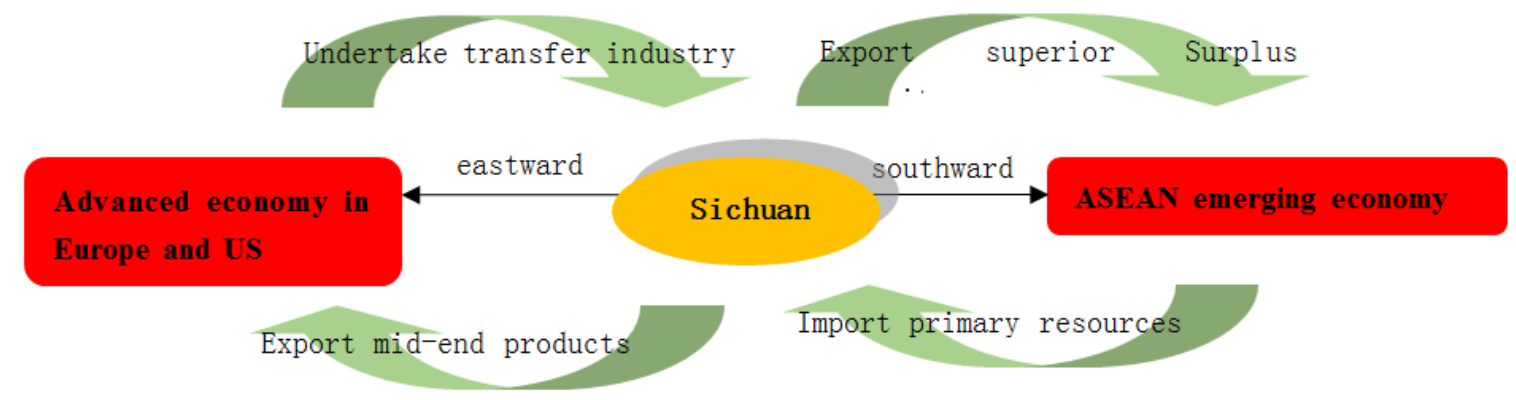

Figure 1. Two-way circulation of value chain of inland open economy (IOE).

\section{The Essential Way: A Comprehensive Comparison with the "Bring in" IRE}

First, the prerequisites are distinguished. The IRE characterized by labor export and resource and energy supply is mainly premised on the lack of sufficient endogenous power for resource and economy development in the territory. As an opening frontier position, the eastern region has obvious geographical advantages and strong factor demand. In comparison, the IOE is characterized by regional openness, industrial undertakings, and production capacity cooperation, and the main premise is that regional resource supply has already faced an inflection point, and the original "the Rough Shu Road" has become "the Smooth Shu Road". The geographical advantages of the Sichuan hinterland are constantly being formed and highlighted by linking the central and eastern regions and by adjoining Southeast Asia. Concurrently, the industrial gradient, capacity complementarity and stage difference of industrialization process among the regional economy provide an endogenous driven force for regional industrial transfer and production capacity cooperation in the eastern regions, Sichuan province and the Southeast Asian [9]. The government's preferential policies which are about the land of industrial transfer and undertaking provide a beneficial system supply.

Second, the main purposes are various. The coastal processing trade model is adapted to the gradual opening pattern of "inland areas are opening to the east areas, and east areas are opening to the overseas". It takes advantage of coastal location to absorb inland production factors inwards, and to undertake international industrial transfers with benefits of factor costs out of China. During this period, it has obvious inherent advantages and terrific prospects. With the development of coastal products trade, the purposes of the IRE not only focuses on regional connectivity about the transportation trunk lines, but also on the cohesive and external effect and the industry-oriented function about the transportation network; the research emphasizes on three-dimensional intermodal transportation based on multiple transportation modes; the transportation system of the Sichuan province can establish a suitable industry system for iron and port, and vigorously develop the inland transportation economy, and then build a regional division of labor system and closed-loop supply chain dominated by Sichuan [8]. are to achieve cross-industry employment of factors through the cross-regional flow of factors, built resource supply areas and reserve sites in the eastern region, and strengthen the degree of utilization of regional resources. IRE drives industrialization with resources, and promotes urbanization with industrialization [10]. The aim can be summarized as "Relying on its own resource advantages, exporting labor elements to the east, building a production base of heavy industry, taking the geographical advantages of the east, indirectly participating in the international division of labor, and regarding resource development as a driving factor to initially complete industrialization and urbanization [11]. While, the IOE aims to build a cross-regional industrial chain, focus on enhancing the local regional allocation capacity and profitable space in the cross-regional industrial chain. It can be summarized as "Taking industrial parks as carriers, undertaking foreign industries, realizing the concentration and agglomeration of similar industries and related industries, striving to achieve capacity replacement and industrial transformation and upgrading through industrial undertaking, and balancing regional development in industrial agglomeration, and promoting the deepening industrialization and urbanization with industrialization as the driving factor".

Third, the core content is different. The IRE focuses on openness of factor and output of resource development, while the IOE gives priority to industrial openness, capacity upgrade and market development. Based on the location advantage of linking the central and eastern regions and adjacent to Southeast Asia, IOE implements a two-way mode opening to the east area and Southeast Asia, and coordinates to undertake the eastern and international transfer industry. While, it explores the emerging markets in Southeast Asia, and strives to achieve multiple competitive advantages and multi-polar market capacity [12]. IOE's core content is the comprehensive use of comparative and latecomer advantages in geographic location, 
resource endowment, traffic conditions, market capacity, environmental carrying capacity and preferential policies [13]. A comprehensive competitive advantage is formed from inland investment attractors and importing intelligence and capital. Industrial replacement is realized by industrial undertaking, and "the Eastern-Sichuan-Southeast Asia circle" is constructed, and then inland opening highlands and industrial clusters lands are built. By stimulating the factors demand for land, capital, and technical within the territory, through the construction of cross-border industrial parks, IOE can accelerate the process of industrialization and urbanization, and release endogenous power of economy development.

Fourth, the industrial pattern is different. IRE's development model is featured by "Opening to the east, promoting industry by mining, and establishing a city by mining". At the industrial structure level, the iron and steel economy and coal economy based on mineral resources are formed. At the spatial structure level, IRE is the spatial distribution pattern of the trinity among resource-rich areas, heavy industry systems and resource-based cities. Significant changes have taken place in the external environment for the development of the IOE industry. The degree of resource substitution has increased, the pace of technological innovation has accelerated, the product life cycle has shortened, industry boundaries have tended to blur, and product function has expanded [14]. For the resource-based industry which is lack of alternative industries and resource supply and tighter ecological constraints, the IOE attaches great importance to the introduction of intervention mechanisms based on resource substitution, technological innovation, industrial upgrading, and ecological compensation under the opening perspective. Then it suppresses the cyclical fluctuations of "Poor resource, weak industry and urban decline". Thus, IOE have guided traditional resource-based industries to transform and upgrade in the "Intensive, efficient, green, innovative and opening" trend. In the dynamic process of regional openness, industrial undertaking and capacity cooperation, Sichuan has simultaneously integrated into the global value chain based on the global division of labor system, the domestic industrial chain based on the domestic industrial system, and the closed-loop supply chain based on the regional transportation system. In Sichuan, it should be vigorously developed an opening economy and the transportation economy, focus on promoting the construction of industrial parks featured by multi-product integration, industry-city integration and function upgrading. The transportation location conditions, resource allocation efficiency and supporting service functions will be improved in industrial gathering places. Consequently, a city of inland transportation hub and a city of inland commercial logistics that are different from resource-based cities are built.

Fifth, the implementation way is different. In view of the established constraints of highly abundant resource, insufficient industrial endogenous power, and market regional segmentation, the IRE is mainly integrated into the "bring in" coastal processing trade model by outputting factors and relying on the radiation effect with coastal export-oriented economy. In the realization of the way, it pays special attention to building a stock matching relationship based on labor factors and primary resource products with the eastern coastal export-oriented economy [15]. IRE aims to seek external demand and exogenous power for regional economic development by establishing incremental adaptation way of product homogeneity, industry isomorphism, and model homology. In the order development of resource, industrial gradient transfer and the gradual integration of the market, the IOE differs in the realization way. For one thing, it attaches importance to the rise of the coastal export-oriented economy from the low-end link to the high-value-added link. During the process, the upstream factor endowment structure is guided by continuously upgrading of the demand structure in downstream market and aimed to realize the "Green, innovative, intensive and opening" goal. At the level of technology path, industrial form, product function and configuration mode, it is carried out leapfrog catching up with the coastal export-oriented economy. For another, it focuses on undertaking advanced industries in the process of capital westward movement, industry inward migration, and factor backflow to achieve the goal of adjusting stocks in increments. IOE also establishes a dynamic balance among resources, industries, and markets with a three-dimensional output of production capacity. It can obtain the main status and location allocation function of the regional supply chain, and realize the transformation of the regional economic development way from resource-driven to open-driven.

\section{Conclusion}

Compared with the IRE, the IOE with the strategy of " the guidance of the transfer of eastern industries with regional openness, and the promotion of industrial structure with capacity cooperation", attends to concentration on the release of the internal vitality and endogenous power of economic development. It emphases that the power of economic development is changed from resource-driven to industry-driven, the development way is converted from factor output to capacity output, and the regional economic form is transformed from resource-based economy to opening economy. The fundamental differences between the two economic models are mainly reflected in prerequisites, main purposes, core content, industrial pattern, and implementation way.

\section{Fund Project}

This article relies on the Panzhihua University $\mathrm{PhD}$ Research Startup Project "Research on Public Art with Water as Media" (035200153) and "Collaborative Research on Sichuan Investment and Trade Policy from a Global Perspective" (035200152). 


\section{References}

[1] Liu Zhibiao, Wu Fuxiang. Double embedding of global value chain under the "Belt and Road Initiative". Chinese Social Sciences, 2018 (08): 17-32.

[2] Hu Ying. Research on China's regional economic development model. Commercial Economic Research, 2019 (15): 160-163.

[3] Wu Qi. A review of the research on the open economy of inland China. New West, 2019 (15): 73-74.

[4] Li Hongbing, Wen Lei, Lin Xuedong. The strategy of "excellent entry and superior exit" of China's foreign trade: a study based on the perspective of product quality and value added rate.

[5] Chen Anna. Research on the development model of the Chinese railway "going global" in the new era. Business Economics Research, 2019 (14): 176-178.

[6] Feng Xiaoyang. Research on the Necessity of Building an Inland Open Economic Highland in Chengdu. Cooperative Economy and Science and Technology, 2019 (15): 4-7.

[7] Shen Jiayan, Wang Fang, Liu Zhenze. Global Opening, Industrial Undertaking and Policy Coordination-Taking the Construction of Open Inland Highlands in Sichuan as an Example. Agricultural Economics and Science and Technology, 2016 (17): 266-267.

[8] Huang Zhuoli. The main path of China 's foreign trade opening and its current characteristics [J]. Modern Marketing (Management Edition), 2020 (01): 70. X.

[9] Fu Xiaodong, Wang Jingtian, Cui Xiaoyu. Regional economic policy practice and theoretical research since the founding of New China [J]. Regional Economic Review, 2019 (04): 8-24. $\mathrm{X}$.

[10] Wang Wenyu. Globalization and the transformation of China 's regional industrial structure $[\mathrm{C}]$. Economic Geography Committee of the Chinese Geographical Society. Summary of the 2019 Annual Meeting of the Economic Geography Committee of the Chinese Geographical Society. Professional Committee of Economic Geography of the Chinese Geographical Society: China Geography Learn, 2019: 13. X.

[11] Li Haiyue. International Economic and Trade Development and my country's Foreign Trade Strategic Choice [J]. China Business Review, 2019 (10): 92-93. X.
[12] Liu Huajun, Jia Wenxing, Peng Ying, Pei Yanfeng. Has the spatial spillover of regional economy narrowed the regional gap? - Empirical evidence from the paradigm of relational data analysis [J]. Economic and Management Review, 2019, 35 (01): 122-133. X.

[13] Si Zengchuo, Zhou Kun, Shao Jun. China's foreign trade upgrade: efficiency improvement and potential realization [J]. Shanghai Economic Research, 2019 (01): 113-128.

[14] Kuang Cuifen. Analysis of my country's foreign trade strategy formulation from the perspective of international economic and trade [J]. Modern Economic Information, 2019 (01): 146.

[15] Li Yinghui, Li Jing. The practice of inland opening in China: mechanism analysis and economic growth effect [J / OL]. Journal of Chongqing Technology and Business University (Social Science Edition): 1-13 [2020-06-01]. http: //kns.cnki.net $/ \mathrm{kcms} /$ detail/50.1154.C.20191227.0922.002.html.

\section{Biography}

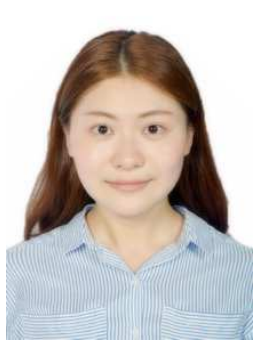

Zeng Liyun, Ph. D candidate of Rattanakosin International College of Creative Entrepreneurship, Rajamangala University of Technology, Rattanakosin - RICE, Bangkok, Thailand, Major in landscape tourism management, Work as a teacher in Civil and Architecture Engineering School, Panzhihua University. Engaged in teaching and scientific research related to urban and rural planning, management, landscape and environment. Host Panzhihua University PhD Research Startup Project "Research on Public Art with Water as Media" (035200153).

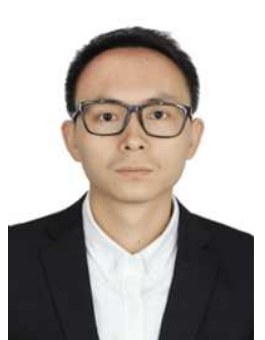

Mao Yunyi, Doctor of Population, Resources and Environmental Economics, Southwestern University of Finance and Economics; Teacher Economics and Management school of Panzhihua University; Host Panzhihua University $\mathrm{PhD}$ Research Startup Project "Collaborative Research on Sichuan Investment and Trade Policy from a Global Perspective" (035200152). 